\title{
A Review of Complications and Outcomes following Vertebral Column Resection in Adults
}

\author{
Sravisht Iyer $^{1}$, Venu M. Nemani ${ }^{2}$, Han Jo Kim ${ }^{1,3}$ \\ ${ }^{1}$ Department of Orthopaedic Surgery, Hospital for Special Surgery, New York, NY, USA \\ ${ }^{2}$ Department of Orthopaedic Surgery, Washington University, St. Louis, MO, USA \\ ${ }^{3}$ Department of Orthopaedic Surgery, Weill Cornell Medical College, New York, NY, USA
}

\begin{abstract}
The correction of rigid spinal deformities in adult patients can require a three-column osteotomy (pedicle subtraction osteotomy [PSO] or vertebral column resection [VCR]) to obtain spinal balance. Unfortunately, the existing adult deformity literature frequently reports the outcomes and complications of these procedures together even though VCR is a more extensive procedure with potentially higher rates of complications. We sought to address this shortcoming and provide clinicians with an overview of the existing literature regarding VCR in adult patients. The goals of this review are: to determine the rate of overall and neurologic complications following VCR, the rate of complications with VCR compared to PSO, and the impact of VCR on clinical and radiographic outcomes. An electronic literature search was used to identify studies reporting outcomes or complications following VCR in adult patients. Raw data on patient demographics, case information, radiographic outcomes, complications and clinical outcomes were extracted. Data were pooled to report a rate of overall complications and neurologic complications. A pooled relative risk of complications following PSO vs. VCR was also calculated. Eleven retrospective studies (Level IV) met our inclusion criteria. The overall rate of complications was $69.2 \%$. The reoperation rate was $9.6 \%$. The rate of neurologic complications was $13.3 \%$ (range, $6.3 \%$ to $15.8 \%$ ) with most cases being transient. The rate of permanent neurologic deficits was $2.0 \%$. We found a significantly higher rate of all complications with VCR compared to PSO (relative risk, 1.36; 95\% confidence interval, 1.24-1.49; $p<0.001$ ). All studies reporting clinical outcomes showed significant improvements in functional outcome postoperatively.
\end{abstract}

Keywords: Vertebral column resection; Three column osteotomy; Pedicle subtraction osteotomy; Spine deformity; Complications; Neurologic complications

\section{Introduction}

The correction of rigid spinal deformity in adult patients can require the use of three-column osteotomies (3COs), specifically pedicle subtraction osteotomies (PSO) and vertebral column resection (VCR). These osteotomies provide the power to correct severe, rigid curves in the coronal, axial and sagittal planes through a posterior-only approach. Their power comes at the cost of considerable technical difficulty and high risk of complications.

PSO is a closing wedge osteotomy hinging on the anterior cortex of the vertebral body. This involves removal of the posterior elements, the pedicles and a V-shape resection through the vertebral body. VCR is a more extensive procedure and involves removal of the entire vertebral body in addition to the adjacent intervertebral discs. However, de-

Received Aug 26, 2015; Revised Oct 4, 2015; Accepted Oct 5, 2015

Corresponding author: Han Jo Kim

Department of Orthopaedic Surgery, Hospital for Special Surgery, 535 E 70th St., New York, NY 10021, USA

Tel: +1-212-774-2837, Fax: +1-646-797-8428, E-mail: hanjokimmd@gmail.com 
spite the more extensive nature of the VCR and the potential for a higher rate of complications, many authors have reported on 3COs as a single entity, by combining PSO and VCR when reporting their outcomes. In addition, much of the current data is from series that include both pediatric and adult patients. This has made it difficult to discern the rate of neurologic and other surgical complications following VCR in adult patients. This review aims to address this limitation by examining the following questions: (1) What is the rate of neurologic and other complications following VCR in adult patients? (2) What is the rate of complications in VCR as compared to PSO? (3) What impact does the use of VCR have on clinical outcomes?

\section{Methods}

\section{Electronic literature search}

We performed a search of PubMed, CINAHL, EMBASE, the Cochrane Library, and Google Scholar for literature published through September 9, 2014. The search was limited to articles in English. Search terms were devised to identify studies that reported outcomes or complications following VCR or any 3CO. Search terms included VCR (vertebral column resection) OR three column osteotomy (Title/Abstract) as well as terms related to complications or outcomes.

Meeting abstracts and proceedings, white papers, editorials and reviews were excluded. We excluded papers where VCR was performed for spine tumors, metastases or in cases of acute trauma. Papers reporting radiographic data, complications or outcomes following 3COs or papers with pediatric patients were included when it was possible to obtain the raw data for the adult VCR cohort. Studies with less than 10 adult VCR cases were excluded.

\section{Data extraction}

From the included articles, the following data were extracted when available: inclusion and exclusion criteria, patient demographics and case details, preoperative and postoperative radiographic data, patient reported outcome measures, and complications.

\section{Data analysis}

We pooled the data from the above studies to determine the overall complication rate. This was done despite heterogeneity in the patient population in order to allow for an appreciation of the "overall" complication rate. Major and minor complications were classified using the method outlined by Auerbach, et al. [1]. We also pooled the reported data on neurologic deficits to provide an "overall" rate of neurologic complications. Clinical outcomes and radiographic data were also reported when available.

In studies that reported outcomes of 3COs, raw data on complications following PSO and VCR were obtained and separated when possible. In articles where the number of complications was not explicitly reported [2], it was calculated using the reported complication rate in each study cohort. These data were then used to create a $2 \times 2$ contingency table and calculate relative risk of complications of VCR vs. PSO as well as the $95 \%$ confidence interval (CI). Significance was calculated using a Fisher Exact Probability Test. Data from each individual study was then pooled to report an overall relative risk as well as confidence interval.

\section{Results}

We were able to identify 11 studies that met the inclusion criteria detailed above (Fig. 1). A detailed description of the studies excluded after full text review is provided

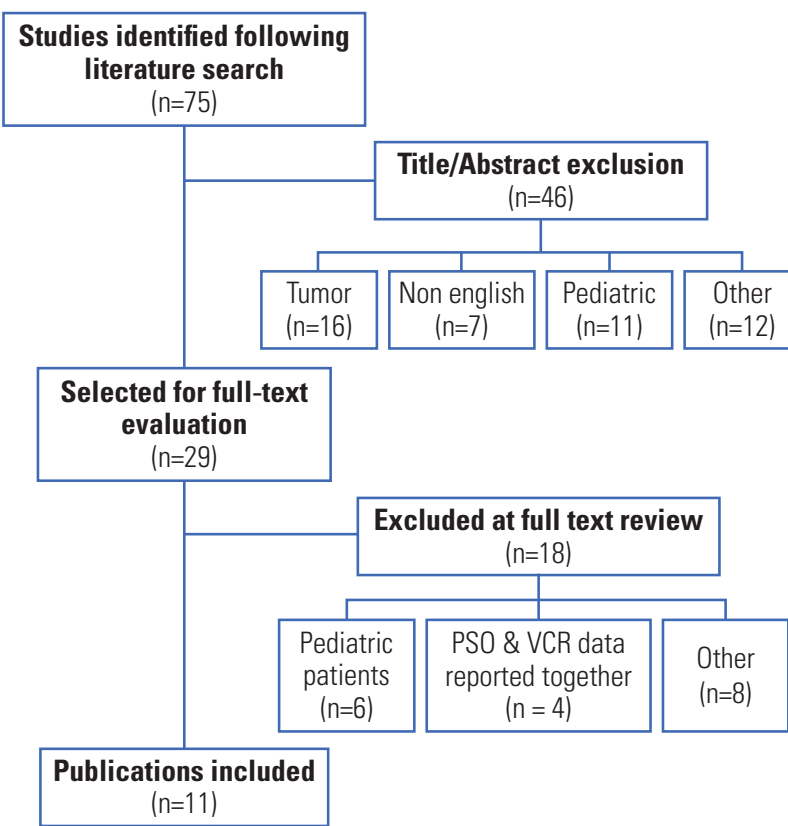

Fig. 1. Flow diagram of article selection. Details about articles selected for full text evaluation and a detailed rationale for article selection is shown in the appendix. PSO, pedicle subtraction osteotomy; VCR, vertebral column resection. 
Table 1. Overview of all included studies with trial design, inclusion criteria and primary outcome examined

\begin{tabular}{|c|c|c|c|}
\hline Reference & Inclusion criteria & Primary outcome & Data extracted \\
\hline Scheer et al. [3], 2014 & 3CO from ISSG & $\begin{array}{l}\text { Relationship between HROOL and } \\
\text { age with VCR/PSO }\end{array}$ & $\begin{array}{l}\text {-Complications } \\
\text { ·HROOL outcomes }\end{array}$ \\
\hline Kelly et al. [4], 2014 & Scoli-RISK-1 database ${ }^{\text {b) }}$, ages $18-80$ & $\begin{array}{l}\text { Comparison between } 3 \mathrm{CO} \text { and } \\
\text { non-3CO posterior reconstruction }\end{array}$ & Complications \\
\hline Auerbach et al. [1], 2012 & $\begin{array}{l}\text { All PSO or VCR from 1995-2008 at a single } \\
\text { institution, } 2 \text { yr follow up }\end{array}$ & $\begin{array}{l}\text { Report of major complications; } \\
\text { comparison between PSO and VCR }\end{array}$ & $\begin{array}{l}\text {-Radiographic data } \\
\text {-Complications } \\
\text { ·HROOL outcomes }\end{array}$ \\
\hline Hassanzadeh et al. [5], 2013 & $\begin{array}{l}\text { Age } \geq 60 \text { with PSO or VCR from 2005-09 } \\
\text { at a single institution, } 2 \text { yr follow up }\end{array}$ & $\begin{array}{l}\text { Use of three column osteotomies in } \\
\text { older patients }\end{array}$ & Complications \\
\hline Xie et al. [6], 2012 & $\begin{array}{l}\text { Posterior VCR, curves }>100 \text { degrees with } \\
\text { limited flexibility }\end{array}$ & $\begin{array}{l}\text { Outcomes of VCR in cases of rigid } \\
\text { deformity }>100^{\circ}\end{array}$ & Radiographic data \\
\hline Lenke et al. [7], 2010 & All VCR from 2002-2006 at a single institution & Outcomes of VCR & $\begin{array}{l}\text {-Radiographic data } \\
\text {-Complications }\end{array}$ \\
\hline Suk et al. [8], 2002 & $\begin{array}{l}215 \text { adults undergoing VCR from 1997-1999, } \\
2 \text { yr follow up }\end{array}$ & Outcomes of VCR in adults & $\begin{array}{l}\text {-Radiographic data } \\
\text {-Complications }\end{array}$ \\
\hline Wang et al. [9], 2008 & $\begin{array}{l}\text { Severe ( }>75 \text { degree sagittal curves), rigid adult } \\
\text { deformity, treated with VCR from 2003-05, } \\
2 \text { yr follow up }\end{array}$ & $\begin{array}{l}\text { Outcomes of a modified posterior } \\
\text { VCR in adults }\end{array}$ & $\begin{array}{l}\text {-Radiographic data } \\
\text {-Complications } \\
\text {-Outcomes }\end{array}$ \\
\hline Suk et al. [10], 2005 & $\begin{array}{l}\text { Consecutive series, VCR for fixed lumbosacral } \\
\text { deformity, } 2 \text { yr follow up }\end{array}$ & $\begin{array}{l}\text { Impact of VCR on fixed lumbo-sacral } \\
\text { deformity }\end{array}$ & $\begin{array}{l}\text {-Radiographic data } \\
\text {-Complications }\end{array}$ \\
\hline Suk et al. [11], 2005 & $\begin{array}{l}\text { Consecutive series, VCR for rigid scoliosis, } \\
2 \text { yr follow up }\end{array}$ & $\begin{array}{l}\text { Impact of VCR in cases of fixed, } \\
\text { rigid scoliosis }\end{array}$ & $\begin{array}{l}\text {-Radiographic data } \\
\text {-Complications }\end{array}$ \\
\hline Zhang et al. [12], 2013 & $\begin{array}{l}\text { Consecutive series, VCR for post-tubercular } \\
\text { deformity }\end{array}$ & $\begin{array}{l}\text { Use of VCR to treat post-tubercular } \\
\text { deformity; literature review }\end{array}$ & $\begin{array}{l}\text {-Radiographic data } \\
\text {-Complications } \\
\text {-Outcomes }\end{array}$ \\
\hline
\end{tabular}

All studies are retrospective review of patients (level IV evidence).

$3 \mathrm{CO}$, three column osteotomy; PSO, pedicle subtraction osteotomy; VCR, vertebral column resection.

a)ISSG, International Spine Study Group: Inclusion criteria-Age $\geq 18$, Cobb $\geq 20^{\circ}$, Sagittal vertical axis $\geq 5 \mathrm{~cm}$, pelvic tilt $\geq 25^{\circ}$, and/or thoracic kyphosis $\geq 60^{\circ}$. Exclusion criteria-neuromuscular deformity, active infection; ${ }^{b}$ Scoli-RISK1, inclusion criteria: age 18-80 years, primary scoliosis, kyphosis, or kyphoscoliosis w/major Cobb angle $\geq 80^{\circ}$ in coronal or sagittal plane, congenital or revision spinal deformity undergoing reconstruction w/an osteotomy (PCO or 3CO), any patient undergoing a 3CO, any patient w/preop myelopathy due to spinal deformity, any patient w/ ossification of the ligamentum flavum or posterior longitudinal ligament \& undergoing a reconstruction w/decompression. Exclusion criteria: Recent history of substance dependency, psychosocial disturbance, active malignancy, active bacterial infection, recent trauma, prior paraplegia, pregnant or nursing.

in the Appendix Tables 1-3. The included articles are shown in Table 1. Only Level IV evidence was available. There were a total of 817 patients in all series; of these, 293 (35.9\%) were adults who underwent VCR. Table 2 highlights the number of adult VCR patients in each trial as well as the case details provided. All averages presented in the results section refer to the adult VCR patients only. Similarly, all percentages are reported in reference to the adult VCR patients only.

\section{Patient demographics and case details}

The average age for the selected studies was 37.4 years (range, 18 to 82 years). For studies where data was available, operating room time averaged $454 \pm 176$ minutes, the number of vertebrae resected was $1.6 \pm 0.8$ (range, 1 to 5 ) and the number of levels fused was $9.5 \pm 4.5$ (range, 2 to 15). Estimated blood loss (EBL) was highly variable across all studies and ranged from 1,278 to $7,413 \mathrm{~mL}$.

\section{Radiographic results}

Eight of the 11 selected articles included preoperative and postoperative radiographic information. These data are summarized in Table 3. The mean coronal curves reported in these series ranged from $37^{\circ}$ to $104^{\circ}$. Similarly, the sag- 
Table 2. Case details of adult VCR cases from selected references

\begin{tabular}{|c|c|c|c|c|c|c|c|c|}
\hline \multirow[b]{2}{*}{ Reference } & \multirow[b]{2}{*}{ Indications } & \multicolumn{2}{|c|}{ No. } & \multirow[b]{2}{*}{ Age (yr) } & \multirow[b]{2}{*}{$\begin{array}{l}\text { OR time } \\
\text { (min) }\end{array}$} & \multirow{2}{*}{$\begin{array}{l}\text { Levels } \\
\text { resected }\end{array}$} & \multirow[b]{2}{*}{$\begin{array}{l}\text { Levels } \\
\text { fused }\end{array}$} & \multirow[b]{2}{*}{$\mathrm{EBL}(\mathrm{mL})$} \\
\hline & & Total & $\begin{array}{l}\text { Adult } \\
\text { VCR }\end{array}$ & & & & & \\
\hline $\begin{array}{l}\text { Scheer et al. [3], } \\
2014\end{array}$ & ASD & 376 & 75 & $\begin{array}{l}51.2 \pm 13.6 \\
(20-82)\end{array}$ & $451 \pm 130$ & NR & NR & $2722 \pm 1951$ \\
\hline Kelly et al. [4], 2014 & ASD & 75 & 19 & NR & NR & NR & NR & NR \\
\hline $\begin{array}{l}\text { Auerbach et al. [1], } \\
2012\end{array}$ & ASD, IS, CK & 105 & 18 & $29 \pm 21.2$ & $518 \pm 94$ & NR & $12.2 \pm 4.1$ & $1278 \pm 859$ \\
\hline $\begin{array}{l}\text { Hassanzadeh et al. } \\
\text { [5], } 2013\end{array}$ & ASD & 51 & 15 & NR & NR & NR & NR & NR \\
\hline Xie et al. [6], 2012 & CK, PIK & 28 & 15 & $\begin{array}{r}30.7 \pm 8.2 \\
(18-45)\end{array}$ & $615 \pm 161$ & 1.3 & $12.3 \pm 3.2$ & $7413 \pm 4978$ \\
\hline $\begin{array}{l}\text { Lenke et al. [7], } \\
2010\end{array}$ & IS, CK, SK, PTK & 43 & 16 & $\begin{array}{l}36.2 \pm 19.7 \\
(18-73)\end{array}$ & $686 \pm 207$ & $1.3 \pm 0.6$ & NR & $1691 \pm 952$ \\
\hline Suk et al. [8], 2002 & ASD, CK, PIK & 70 & 70 & $\begin{array}{c}27.4 \\
(18-64)\end{array}$ & 271 & NR & $6.3(2-15)$ & $\begin{array}{c}2334 \\
(800-4200)\end{array}$ \\
\hline Wang et al. [9], 2008 & CK & 13 & 13 & $\begin{array}{r}31 \pm 8.1 \\
(20-43)\end{array}$ & $266 \pm 45$ & $2.5 \pm 0.4$ & $7.7 \pm 1.4$ & $2412 \pm 507$ \\
\hline Suk et al. [10], 2005 & CK, PIK, PTK & 25 & 21 & $\begin{array}{l}45.5 \pm 12.7 \\
(25-69)\end{array}$ & $\begin{array}{c}280 \\
(190-405)\end{array}$ & $2.2 \pm 1.3$ & $\begin{array}{c}4.5 \\
(2-8)\end{array}$ & $\begin{array}{c}2810 \\
(320-5460)\end{array}$ \\
\hline Suk et al. [11], 2005 & PS, IS, CK & 16 & 16 & $\begin{array}{c}28.94 \pm 7.09 \\
(20-38)\end{array}$ & $371 \pm 82$ & $1.3 \pm 0.5$ & $12.3 \pm 2.7$ & $7034 \pm 2848$ \\
\hline $\begin{array}{l}\text { Zhang et al. [12], } \\
2013\end{array}$ & PIK & 15 & 15 & $\begin{array}{c}35.8 \pm 12.2 \\
(20-60)\end{array}$ & $446 \pm 93$ & $1.3 \pm 0.5$ & $7.8 \pm 1$ & $1653 \pm 778$ \\
\hline
\end{tabular}

VCR, vertebral column resection; OR, operating room; EBL, estimated blood loss; ASD, adult spinal deformity; NR, not reported for adult VCR; IS, idiopathic scoliosis; CK, congenital kyphoscoliosis; PIK, post infectious kyphosis; SK, Scheuermann's Kyphosis; PTK, post-traumatic kyphosis; PS, paralytic scoliosis.

Table 3. Radiographic results in adult VCR patients

\begin{tabular}{|c|c|c|c|c|c|c|c|c|c|c|}
\hline \multirow[b]{2}{*}{ Reference } & \multicolumn{4}{|c|}{ Preoperative radiographs } & \multicolumn{4}{|c|}{ Postoperative radiographs } & \multicolumn{2}{|c|}{$\%$ Correction } \\
\hline & $\begin{array}{l}\text { Cor } \\
\text { Cobb }\end{array}$ & $\begin{array}{l}\text { Sag } \\
\text { Cobb }\end{array}$ & $\begin{array}{l}\text { SVA } \\
(\mathrm{mm})\end{array}$ & $\begin{array}{l}\text { CVA } \\
(\mathrm{mm})\end{array}$ & $\begin{array}{l}\text { Cor } \\
\text { Cobb }\end{array}$ & $\begin{array}{l}\text { Sag } \\
\text { Cobb }\end{array}$ & $\begin{array}{c}\text { SVA } \\
(\mathrm{mm})\end{array}$ & $\begin{array}{l}\text { CVA } \\
(\mathrm{mm})\end{array}$ & $\begin{array}{l}\text { Cor } \\
(\%)\end{array}$ & $\begin{array}{l}\text { Sag } \\
(\%)\end{array}$ \\
\hline $\begin{array}{l}\text { Auerbach et al. [1], } \\
2012\end{array}$ & NR & NR & $-4 \pm 40$ & $5 \pm 18$ & NR & NR & $-28 \pm 31$ & $-17 \pm 21$ & NR & NR \\
\hline Xie et al. [6], 2012 & $104 \pm 30$ & $101 \pm 27$ & NR & NR & $44 \pm 17$ & $31 \pm 12$ & NR & NR & 58.1 & 69.6 \\
\hline Lenke et al. [7], 2010 & $86 \pm 43$ & $92 \pm 32$ & NR & NR & $39 \pm 19$ & $39 \pm 17$ & NR & NR & 54.4 & 58.0 \\
\hline Suk et al. [8], 2002 & $67 \pm 30$ & $44 \pm 25^{\text {a) }}$ & $33(16-69)$ & $32(21-65)$ & $22 \pm 18$ & $4 \pm 21^{a)}$ & $6(-2$ to17) & $10(0-22)$ & 67.2 & 90.9 \\
\hline Wang et al. [9], 2008 & $80 \pm 11$ & $86 \pm 9$ & $42 \pm 6$ & $29 \pm 12$ & $34 \pm 6$ & $32 \pm 6$ & $28 \pm 7$ & $17 \pm 8$ & 57.7 & 62.8 \\
\hline Suk et al. [10], 2005 & $37 \pm 8$ & $36 \pm 25$ & $96 \pm 57$ & $28 \pm 23$ & $15 \pm 7$ & $9 \pm 8$ & $50 \pm 49$ & $17 \pm 10$ & 58.6 & 75.4 \\
\hline Suk et al. [11], 2005 & $109 \pm 20$ & NR & $42 \pm 60$ & $40 \pm 12$ & $46 \pm 15$ & NR & $16 \pm 22$ & $10 \pm 9$ & 58.2 & NR \\
\hline Zhang et al. [12], 2013 & NR & $92 \pm 9$ & NR & NR & NR & $37 \pm 9$ & NR & NR & NR & 60.0 \\
\hline
\end{tabular}

VCR, vertebral column resection; SVA, sagittal vertical axis; CVA, coronal vertical axis; Cor, coronal; Sag, sagittal; NR, not reported.

${ }^{\text {a) }}$ nly includes 38 patients with congenital kyphoscoliosis. 
ittal curves ranged from $36^{\circ}$ to $101^{\circ}$. The use of a posterior VCR was a powerful tool in correcting deformity; correction ranged from $54 \%$ to $67.2 \%$ in the coronal plane and from $60 \%$ to $90.9 \%$ in the sagittal plane.

\section{Complications}

\section{1) All complications}

Table 4 lists the complications associated with VCR. Because there is substantial heterogeneity in the definition of "major" and "minor" complications following 3CO, we have summarized the complications described in each citation. Two of the 11 studies were excluded from the analysis. One study noted "no neurologic and vascular complications" but did not further specify [12], and the second did not separate pediatric and adult complications [6].

The included studies reported a $69.2 \%$ (range, $23.8 \%$ to $100 \%)$ rate of overall complications following VCR [1,35,7-11]. Using data from the seven studies where major and minor complications could be separated [1,5,7-11], we found a $27.7 \%$ rate of major complications as previously defined [1].

Five of the 11 articles selected specified individual complications. These articles included 136 patients with a complication rate of $34 \%$ (range, $23.8 \%$ to $56.3 \%$ ) [7-11]. Neurologic and pulmonary complications were the most common. Common pulmonary complications included pneumothorax $(n=6,4.4 \%)[8,9,11]$, pleural effusions $(n=3,2.2 \%)$ [7], and pulmonary effusion $(n=1)$ [7]. Other reported non-neurologic complications included fixation failures $(n=5)$, compression fractures $(n=2)$, proximal junctional kyphosis $(n=1)$ and pseudarthrosis $(n=1)$ [711]. Thirteen re-operations were reported (9.6\%) [7-11]. Reasons for re-operation included re-exploration for neurologic deficits $(n=3)[8,11]$, decompression of cauda equina $(n=6)[10]$, instrument failure $(n=2)$ [8], pseudarthrosis $(n=1)$ [8], and coronal and sagittal imbalance $(n=1)$ [7].

Finally Auerbach et al. [1] attempted to identify riskfactors for complications in all patients undergoing $3 \mathrm{CO}$ (PSO or VCR). They were able to show preoperative sagittal imbalance $\geq 40 \mathrm{~mm}(p=0.01)$, age $\geq 60(p=0.01)$ and the presence of 3 or more medical comorbidities $(p=0.04)$ as risk factors for complications.

\section{2) Neurologic complications}

Neurological complications are also detailed in Table 4. Of the nine articles included in the analysis of complications, one was excluded because it did not report neurologic complications separately [3]. The second was excluded as it did not separate neurologic complications for VCR and PSO [5]. This left seven articles that reported the number of neurologic complications [1,4,7-11].

The seven remaining articles included 173 patients with 23 neurologic complications, a rate of $13.3 \%$ (range, $6.3 \%$ to $15.8 \%$ ). Kelly et al. [4] did not specify if the neurologic deficits observed in patients with VCR were transient or permanent. Excluding their data revealed 20 complications in 153 patients (13\%; range, $6.3 \%$ to $15.4 \%$ ). Of these 20 complications, 17 were transient and all but one returned to normal by 6 weeks [1,7-11]. One case required 6 months before the patient returned to their baseline [10]. There were 3 complete cord injuries observed in these series, resulting in a permanent complication rate of $2.0 \%$ [1,7-11]. All 3 patients with complete cord injuries had Beal's Syndrome and had preoperative neurologic impairment (Table 4) $[8,11]$.

\section{3) VCR vs. PSO}

Four of the selected references [1,3-5] included all 3COs and made an attempt to compare PSO to VCR. Kelly et al. [4] found that patients undergoing VCR were more likely to suffer from a perioperative complication compared to those who underwent PSO (VCR: $73.7 \%$ vs. PSO: $46.9 \%$, $p=0.03$ ). Auerbach et al. [1] found the opposite trend; a higher rate of minor complications (PSO: 53\% vs. VCR: $28 \%, p=0.07$ ) and complications requiring revision (PSO: $20 \%$ vs. VCR: $0 \%, p=0.07$ ) in the PSO group. Hassanzadeh et al. [5] reported a higher rate of major complications following VCR (VCR: 4/15, 26.7\% vs. PSO: 5/38, 13.2\%) but this was not significant $(p=0.42)$. Finally, Scheer et al. [3] reported that VCR did not have an increased rate of intraoperative $(p>0.05)$ or postoperative $(p>0.05)$ complications compared to PSO when stratified by age group. They did not perform an analysis of the overall rate of complications, i.e., intraoperative and postoperative complications.

The data above was pooled to calculate an overall relative risk of complications for VCR vs. PSO. Results of this analysis are shown in Fig. 2. Analysis of the pooled data revealed a significantly higher rate of all complications with VCR vs. PSO (VCR: 87.4\%, PSO: 64.3\%, RR: 1.36, 95\% CI: $1.24-1.49, p<0.001)$. The raw data used to calculate the pooled relative risk can be found in the appendix. 
Table 4. Detailed complication rates for adult patients undergoing VCR

\begin{tabular}{|c|c|c|c|c|}
\hline \multirow{2}{*}{ Reference } & \multicolumn{2}{|r|}{ All complications } & \multicolumn{2}{|r|}{ Neurologic Complications } \\
\hline & No. $(\%)$ & Details & No. $(\%)$ & Details \\
\hline Scheer et al. [3], 2014 & $75(100)$ & $\begin{array}{l}\text { Specific complications not described. } \\
50(66.7 \%) \text { postoperative complications, } \\
25(33.3 \%) \text { "major" intraoperative } \\
\text { complications. No significant difference } \\
\text { compared to PSO. }\end{array}$ & NR & NR \\
\hline Kelly et al. [4], 2014 & 14 (73.7) & $\begin{array}{l}\text { 14/19 VCR patient with a perioperative } \\
\text { complication }\end{array}$ & $3(15.8)$ & 3/19 in VCR-"new neurologic deficit" \\
\hline $\begin{array}{l}\text { Auerbach et al. [1], } \\
2012\end{array}$ & $12(66.7)$ & $\begin{array}{l}12 \text { Total complications ( } 5 \text { major, } 7 \text { minor) } \\
\text { in } 9 \text { VCR patients. Further details not } \\
\text { reported for VCR cohort. }\end{array}$ & $1(5.6)$ & $\begin{array}{l}1 / 18 \text { VCR patients with sensory deficit, } \\
\text { resolved in } 4 \text { weeks }\end{array}$ \\
\hline $\begin{array}{l}\text { Hassanzadeh et al. [5], } \\
2013\end{array}$ & $10(66.7)$ & $\begin{array}{l}4 \text { Major and } 6 \text { minor complications in } \\
\text { the VCR cohort. Further details not } \\
\text { reported for VCR cohort. }\end{array}$ & NR & NR \\
\hline Lenke et al. [7], 2010 & $9(56.3)$ & $\begin{array}{l}9 \text { Total complications, NMEP loss } \times 2 \text {, } \\
\text { pleural effusion } \times 2 \text {, pulmonary effusion, } \\
\text { respiratory failure } \times 1 \text {, revision PSF } 2 \text { yrs } \\
\text { later, rod fracture }\end{array}$ & $2(12.5)$ & $\begin{array}{l}2 \text { Patients with NMEP loss intraoperatively, } \\
1 \text { failed intraoperative wake up test but had } \\
\text { normal final wake up test }\end{array}$ \\
\hline Suk et al. [8], 2002 & $24(34.3)$ & $\begin{array}{l}2 \text { Cord injuries, } \\
6 \text { hematomas (cauda equina) } \\
4 \text { root injuries, } 5 \text { fixation failures, } \\
2 \text { infections, } 5 \text { hemopneumothorax }\end{array}$ & $12(17.1)$ & $\begin{array}{l}\text { Permanent: Complete cord injury in } 2 \\
\text { patients with Beal's syndrome; preoperative } \\
\text { neurologic compromise (Frankel D) } \\
\text { Transient: } 6 \text { cauda equina syndrome due to } \\
\text { hematoma, recovered after decompression; } \\
4 \text { transient nerve root injuries all recovered }\end{array}$ \\
\hline Wang et al. [9], 2008 & $4(30.8)$ & $\begin{array}{l}4 \text { Total complications, } \\
2 \text { transient neuro deficits, } \\
1 \text { wound problem, } \\
1 \text { pleural membrane rupture }\end{array}$ & $2(15.4)$ & $\begin{array}{l}1 \text { Patient improved without intervention, } \\
1 \text { patient was ASIA C postoperatively, } \\
\text { received methylprednisolone and improved } \\
\text { to ASIA E by } 6 \text { weeks. }\end{array}$ \\
\hline Suk et al. [10], 2005 & $5(23.8)$ & $\begin{array}{l}2 \text { Compression fractures, } \\
2 \text { transient neurologic complaints, } \\
1 \text { proximal pseudarthrosis }\end{array}$ & $2(9.5)$ & $\begin{array}{l}1 \text { Patient with grade } 3 \text { motor weakness, } \\
\text { normal in } 6 \text { months; } 1 \text { patient with } \\
\text { preoperative L } 5 \text { radiculopathy had transient } \\
\text { postoperative neurologic complaints }\end{array}$ \\
\hline Suk, et al. [11], 2005 & $4(25)$ & $\begin{array}{l}1 \text { Hematoma, } 1 \text { paralysis, } \\
1 \text { hemopneumothorax, } \\
1 \text { proximal junctional kyphosis }\end{array}$ & $1(6.3)$ & $\begin{array}{l}\text { Complete postoperative paralysis in a } \\
\text { patient that was Frankel C preoperatively, } \\
\text { Beal's syndrome }\end{array}$ \\
\hline
\end{tabular}

Neurologic complications are highlighted.

VCR, vertebral column resection; PSO, pedicle subtraction osteotomy; NR, not reported; NMEP, neurogenic motor evoked-potential monitoring; PSF, posterior spinal fusion.

\section{Clinical outcomes}

Four studies reported clinical outcomes, which uniformly improved following VCR $[1,3,9,12]$. The results are summarized in Table 5. Scheer et al. [3] sought to examine the impact of age on clinical outcomes. They reported the change in the 36-Item Short-Form Health Survey (SF-36, Physical Component Summary [PCS] and Mental Component Summary [MCS]), visual analog scale (VAS), Os- westry disability index (ODI) and the Scoliosis Research Society-22 questionnaire (SRS-22, subdomains: activity, pain, satisfaction, mental, appearance and total). In their series of all 3COs, they were able to show a significant improvement between preoperative and postoperative scores for all of the above measures [3]. Compared to older patients (age $\geq 65$ years), young patients (age $\leq 45$ years) undergoing VCR had greater improvement and were more likely to meet MCID in 2-year SRS pain, SRS function, 


\section{Complications, VCR vs. PSO}

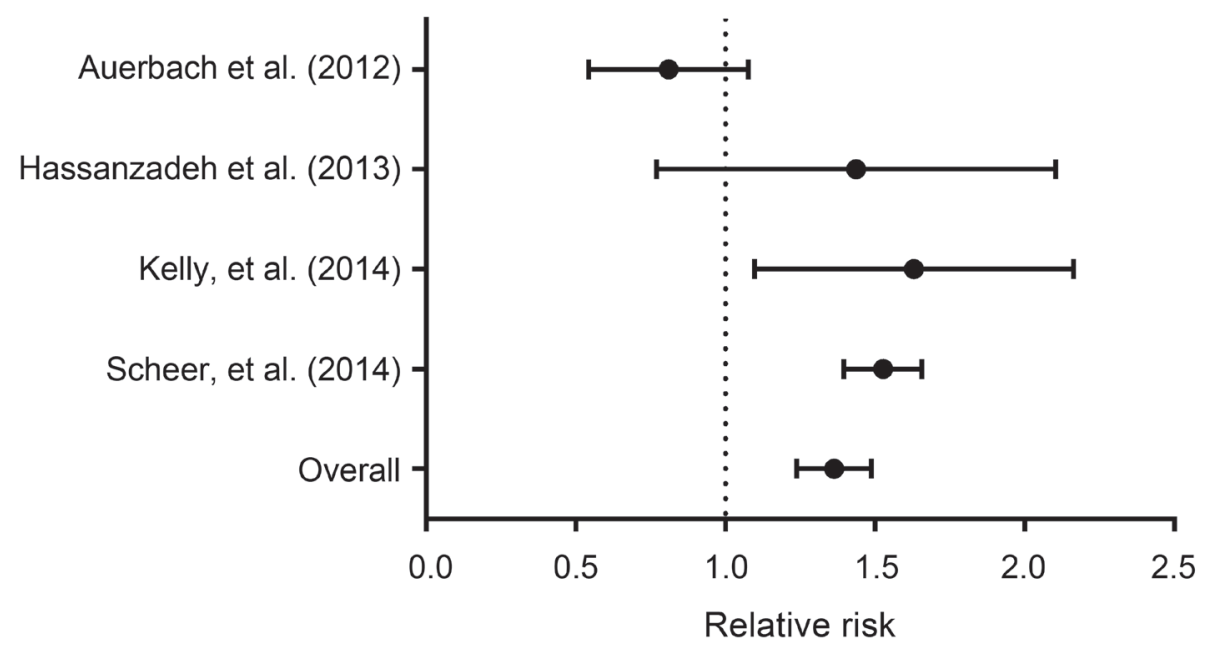

Fig. 2. Relative risk (RR) of complications with VCR vs. PSO. There was an increased risk of complications (RR, 1.36; 95\% confidence interval, 1.24-1.49) when data from the above studies was pooled for analysis. VCR, vertebral column resection; PSO, pedicle subtraction osteotomy.

Table 5. Studies reporting clinical outcome measures for patients undergoing VCR

\begin{tabular}{ll}
$\begin{array}{l}\text { Reference } \\
\text { Scheer et al. [3], 2014 }\end{array}$ & $\begin{array}{l}\text { Oll patients with significant improvement in HROOL. HROOL improvement with VCR more pronounced in young } \\
\text { (age } \leq 45 \text { yr) compared to old (age 65) patients in: 1-year SRS pain, 1 and 2-year PCS, 2-year ODI. Young also with } \\
\text { improved } 1 \text { yr PCS outcomes compared to middle-aged group (45-65). }\end{array}$ \\
\hline Auerbach et al. [1], 2012 & $\begin{array}{l}\text { Significant improvement in the self-image and overall subscore of SRS-24 with VCR, no significant improvement } \\
\text { in pain or function subscores; No difference in satisfaction compared to PSO. }\end{array}$ \\
\hline Wang et al. [9], 2008 & $\begin{array}{l}\text { Improvement in VAS from 1.77 to 0.54, improvement in SRS-24 scale from 38.15 to 76.92, } \\
\text { significant in all subscales. }\end{array}$ \\
\hline Zhang et al. [12], 2013 & Significant improvement in ODI (46.5 to 5.7), VAS (8.7 to 2.2). \\
\hline
\end{tabular}

VCR, vertebral column resection; HROOL, health related quality-of-life; SRS, Scoliosis Research Society; PCS, physical component summary of the short form 36 (SF-36) functional outcome measure; ODI, Oswestry disability index; VAS, visual analog scale; PSO, pedicle subtraction osteotomy.

1-year PCS and 2-year PCS scores [3].

Auerbach et al. [1] evaluated patients using the SRS24 instrument (subdomains: pain, function, self-image, total subscore). The clinical outcomes still improved even if patients experienced a complication. Wang et al. [9] showed a significant improvement in VAS from $1.8 \pm 2.2$ to $0.5 \pm 1.1(p<0.05)$ and SRS-24 total scores $(38.2 \pm 5.4$ to $77 \pm 6.2, p<0.05)$. Zhang et al. [12] also reported significant improvements in VAS and ODI.

\section{Discussion}

The data presented summarizes our current understanding of the complications and outcomes following VCR in adult patients. Correction after VCR ranged from 54\% to $67.2 \%$ in the coronal plane and from $60 \%$ to $90.9 \%$ in the sagittal plane. There was an overall complication rate of $69.2 \%$ (range, $23.8 \%$ to $100 \%$ ). In the studies where individual complications were reported, we calculated a major complication rate of $27.7 \%$. We also found using pooled data that the relative risk of overall complications is higher with VCR compared to PSO. However, and most importantly, clinical outcomes were improved after VCR despite the high complication rate.

When data for complications was available, neurologic complications were the most common, followed by pulmonary complications (pneumothorax, pleural effusion) and fixation failure. The rate of all neurologic complications was $13.3 \%$ (range, $6.3 \%$ to $15.8 \%$ ). One important finding of this study was that most neurologic complica- 
tions were transient in nature; of the 23 patients with neurologic deficits, 19 had resolved within six weeks, one required 6 months and three patients had permanent deficits. Indeed, all patients with permanent deficits had some preoperative neurologic deficits. Although the small number of these cases and the low overall level of evidence (Level IV) in the literature makes it impossible to make any further conclusions, it does appear that special care must be taken when performing VCR in patients with preoperative neurologic deficits. In addition, VCR should not be performed when intraoperative monitoring cannot be utilized.

In addition to calculating the overall complication rate, we compared the rate of complications with VCR vs. PSO. A number of series in the literature previously have examined outcomes in patients undergoing $3 \mathrm{CO}$ but prior to this analysis, it was difficult to determine if there truly was a difference in complication rate between VCR and PSO. Auerbach et al. [1] reported a higher complication rate with the use of PSO though this was not significant. On the contrary, Hassanzadeh et al. [5] and Scheer et al. [3] reported a higher rate of complications with VCR but this did not reach statistical significance. In the latter study, no analysis of overall complication rate was performed, but the data presented was age stratified and examined intraoperative and postoperative complications separately [3]. Kelly et al. [4] concluded that VCR is associated with a higher rate of complications. Using raw data from these trials, however, we were able to clearly show that patients undergoing VCR are at higher risk for complications compared to those treated with PSO. This is an important finding as the risk of complication is an important consideration when planning osteotomies for deformity correction. However, caution must again be used when interpreting our results given the disparate reporting of complications and underlying low level of evidence.

Finally, all studies reported an improvement in postoperative functional measures $[1,3,9,12]$. In fact, Auerbach et al. [1] showed that these patients' postoperative functional outcome scores improve even if they experienced postoperative complications. There was insufficient data to perform any further analysis or reach any further conclusions regarding clinical outcomes.

The data presented above focuses primarily on the risk of complications associated with VCR. There is, unfortunately, minimal data to guide our decision making regarding prevention of these complications. Auerbach et al. [1] reported that an increase preoperative sagittal balance ( $>40 \mathrm{~mm}$ ), age $>60$ years and 3 or more medical comorbidities were all risk factors for complications following this procedure. Buchowski et al. [2] reported a $2.8 \%$ rate of permanent deficit in a series of 108 PSOs and surmised that patients with a permanent deficit had inadequate decompression, subluxation or buckling of the dura. While these findings alone do not provide guidance on specific techniques that might prevent complications following $3 \mathrm{CO}$, they do highlight the importance of patient selection and meticulous surgical technique when attempting to minimize complications following 3COs.

The data presented above has a number of important limitations. First, there is currently no prospective data available regarding the complications and outcomes following VCR. Therefore, we are limited only to Level IV evidence, which makes it difficult to draw any strong conclusions. Second, the series above span over a decade of data (cases performed starting in 1997) during which there have been tremendous advances in both technique and instrumentation as experience with VCR has grown. Third, there are a wide variety of indications for VCR in the series described above ranging from congenital kyphoscoliosis to post-infectious kyphosis and adult deformity. This introduces substantial heterogeneity into the patient population and limits the strength of any pooled analysis. Finally, because we have chosen to limit our focus to adult VCR patients, we are limited by the way in which certain authors have reported data. There were several series where it was not possible to separate adult and pediatric patients or PSO and VCR data. It is likely we would have been able to include several more patients and controlled for more variables like VCR level, if more data had been reported on a case-by-case basis.

Nonetheless, we believe that the current analysis provides substantial value. The VCR is a technically complex, challenging procedure that is reserved for the most severe, rigid curves. This makes it a difficult technique to study prospectively. Additionally, the relative rarity of the procedure also makes it difficult for single center series to provide the numbers required for a comprehensive analysis. This study provides a reference which allows spine surgeons to weigh the available evidence regarding complications following adult VCR and counsel their patients accordingly. We show a high complication rate following VCR but improvement in functional outcomes. Further, we show that complication rates following VCR 
are significantly higher than those after PSO.

\section{Conflict of Interest}

No potential conflict of interest relevant to this article was reported.

\section{References}

1. Auerbach JD, Lenke LG, Bridwell KH, et al. Major complications and comparison between 3-column osteotomy techniques in 105 consecutive spinal deformity procedures. Spine (Phila Pa 1976) 2012;37:1198-210.

2. Buchowski JM, Bridwell KH, Lenke LG, et al. Neurologic complications of lumbar pedicle subtraction osteotomy: a 10-year assessment. Spine (Phila Pa 1976) 2007;32:2245-52.

3. Scheer JK, Lafage V, Smith JS, et al. Impact of age on the likelihood of reaching a minimum clinically important difference in 374 three-column spinal osteotomies: clinical article. J Neurosurg Spine 2014;20:306-12.

4. Kelly MP, Lenke LG, Shaffrey CI, et al. Evaluation of complications and neurological deficits with threecolumn spine reconstructions for complex spinal deformity: a retrospective Scoli-RISK-1 study. Neurosurg Focus 2014;36:E17.

5. Hassanzadeh H, Jain A, El Dafrawy MH, et al. Threecolumn osteotomies in the treatment of spinal deformity in adult patients 60 years old and older: outcome and complications. Spine (Phila Pa 1976) 2013;38:726-31.

6. Xie J, Wang Y, Zhao Z, et al. Posterior vertebral column resection for correction of rigid spinal deformity curves greater than 100 degrees. J Neurosurg Spine 2012;17:540-51.

7. Lenke LG, Sides BA, Koester LA, Hensley M, Blanke KM. Vertebral column resection for the treatment of severe spinal deformity. Clin Orthop Relat Res 2010;468:687-99.

8. Suk SI, Kim JH, Kim WJ, Lee SM, Chung ER, Nah $\mathrm{KH}$. Posterior vertebral column resection for severe spinal deformities. Spine (Phila Pa 1976) 2002;27:2374-82.

9. Wang $\mathrm{Y}$, Zhang $\mathrm{Y}$, Zhang X, et al. A single posterior approach for multilevel modified vertebral column resection in adults with severe rigid congenital kyphoscoliosis: a retrospective study of 13 cases. Eur Spine J 2008;17:361-72.

10. Suk SI, Chung ER, Lee SM, Lee JH, Kim SS, Kim JH. Posterior vertebral column resection in fixed lumbosacral deformity. Spine (Phila Pa 1976) 2005;30:E70310.

11. Suk SI, Chung ER, Kim JH, Kim SS, Lee JS, Choi WK. Posterior vertebral column resection for severe rigid scoliosis. Spine (Phila Pa 1976) 2005;30:1682-7.

12. Zhang HQ, Li JS, Liu SH, et al. The use of posterior vertebral column resection in the management of severe posttuberculous kyphosis: a retrospective study and literature review. Arch Orthop Trauma Surg 2013;133:1211-8. 